\title{
CARACTERIZAÇÃO HIDROGEOLÓGICA EM ASSENTAMENTO NA REGIÃO OESTE DO ESTADO DE SÃO PAULO
}

\author{
Andréa Segura Franzini ${ }^{1}$; Chang Hung Kiang ${ }^{2}$; Flávio de Paula e Silva ${ }^{3}$
}

\section{RESUMO}

Perfis geofísicos e dados de poços constituíram importantes ferramentas para o entendimento do arcabouço hidrogeológico da área do assentamento Margarida Alves, região oeste do Estado de São Paulo. Foram reconhecidas as formações Santo Anastácio e Caiuá, separadas por superfície de discordância regional evidenciada nos perfis geofísicos. As referidas formações constituem unidades aquíferas homônimas que representam o Sistema Aquífero Bauru (SAB). A baixa continuidade lateral de fácies, característica de depósitos fluviais, não permitiu uma correlação litofaciológica em nível de detalhe. Com base em testes de bombeamento, verificou-se que as características hidrodinâmicas dos aquíferos Caiuá e Santo Anastácio são similares. As águas do SAB apresentam distintas composições químicas: as do Aquífero Santo Anastácio foram classificadas como bicarbonatadas magnesianas e as do Aquífero Caiuá como bicarbonatadas cálcicas. O fluxo subterrâneo local, de natureza livre, tem direção SW e área de descarga no ribeirão Nhancá.

\section{ABSTRACT}

Geophysical logs and water well data constitute important tools for understanding the hydrogeologic framework of the Margarida Alves settlement, located in western Sao Paulo State. Two lithostratigraphic formations - Santo Anastácio and Caiuá - separated by an unconformity were recognized. These formations are water-bearing units of the multi-layered Bauru Aquifer System (SAB). The small lateral-continuity of facies, typical of fluvial deposits, didn't allow detailed lithofacies correlation. Pumping tests showed the same hydrodynamic characteristics for the aquifers Santo Anastácio and Caiuá. Two distinct type of groundwater have been identified in the $\mathrm{SAB}$ - bicarbonated-magnesian waters in Santo Anastácio aquifer and bicarbonated-calcium waters in Caiuá Aquifer. The groundwater flows in SW direction and discharges in Nhancá river.

Palavras Chave: Sistema Aquífero Bauru; Perfilagem geofísica; Hidroquímica.

1 - Companhia de Pesquisa de Recursos Minerais. Rua Costa, 55 - São Paulo - SP - (11) 3775-5135 - andrea.franzini@ cprm.gov.br 


\section{INTRODUÇÃO}

A área de estudo trata-se de um assentamento implantando pelo Instituto Nacional de Colonização e Reforma Agrária, INCRA, denominado Assentamento Margarida Alves. Situado no município de Mirante do Paranapanema, região sudoeste do Estado de São Paulo a uma distância de $630 \mathrm{~km}$ da capital (Figura 1).

A região oeste do Estado de São Paulo tem como principal fonte de abastecimento público ou privado de água o Sistema Aquífero Bauru (SAB), que além de servir como manancial é também responsável pela manutenção da vazão dos rios durante os períodos de estiagem (DAEE 1990). O SAB é constituído pelas unidades litoestratigráficas do Grupo Bauru, Cretáceo da Bacia do Paraná. No Estado de São Paulo ocupa área aproximada de $97000 \mathrm{~km}^{2}$ e limita-se a oeste e noroeste pelo rio Paraná, a norte pelo rio Grande, a sul pelo rio Paranapanema e na porção leste pelas áreas de afloramento da Formação Serra Geral.

Nessa área o arcabouço do SAB é constituído pelas formações Caiuá, inferior, e Santo Anastácio, superior, que regionalmente constituem excelentes aquíferos (Figura 1).

O estudo integrou as informações obtidas com a perfuração de cinco poços tubulares pela Companhia de Pesquisa de Recursos Minerais - CPRM, em 2007, para suprir a demanda de água potável do assentamento. O estudo integrou perfis geofísicos, dados de testes de bombeamento, análises químicas de água dos poços e descrições de amostras de calha.

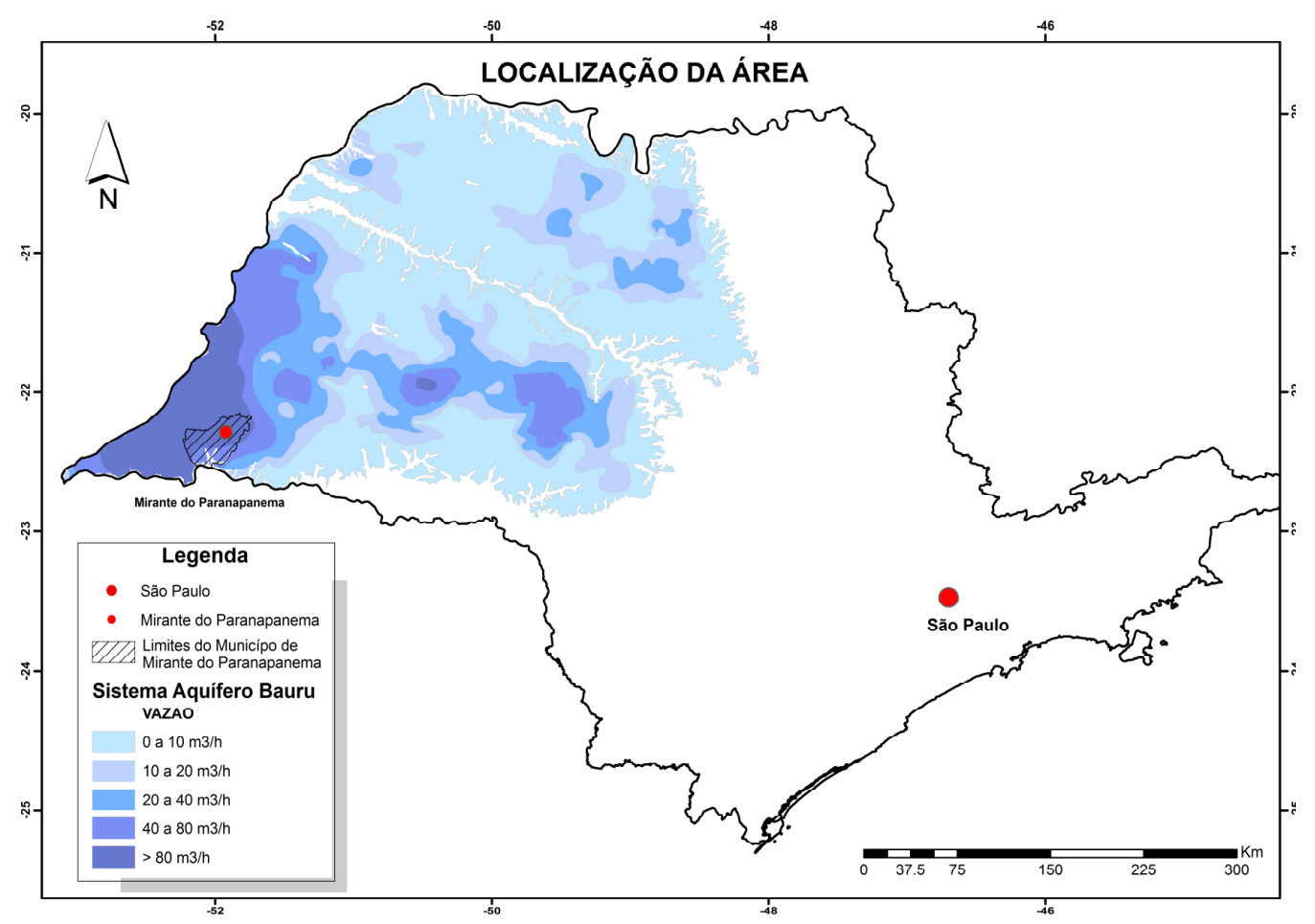

Figura 1. Mapa de potencialidades do SAB (DAEE, 2005), com localização da área. 


\section{CONTEXTO GEOLÓGICO-HIDROGEOLÓGICO}

Estudos baseados em perfis geofísicos e dados de poços profundos perfurados para captação de água subterrânea realizados por Paula e Silva (2003) permitiram estabelecer o arcabouço estratigráfico de subsuperfície do Grupo Bauru, no Estado de São Paulo. Duas superfícies de discordância regionais - S1 e S2 - foram identificadas por esses autores e constituem excelentes horizontes-guia para distinção e delimitação de unidades geofísicas, correspondentes às unidades litoestratigráficas formais. A superfície S1 delimita os estratos atribuídos às formações Caiuá e Pirapozinho abaixo e Santo Anastácio acima; a S2 marca o contato entre a Formação Santo Anastácio, inferior, e os sedimentos das formações Birigui, Araçatuba, e Adamantina acima (Figura 2).

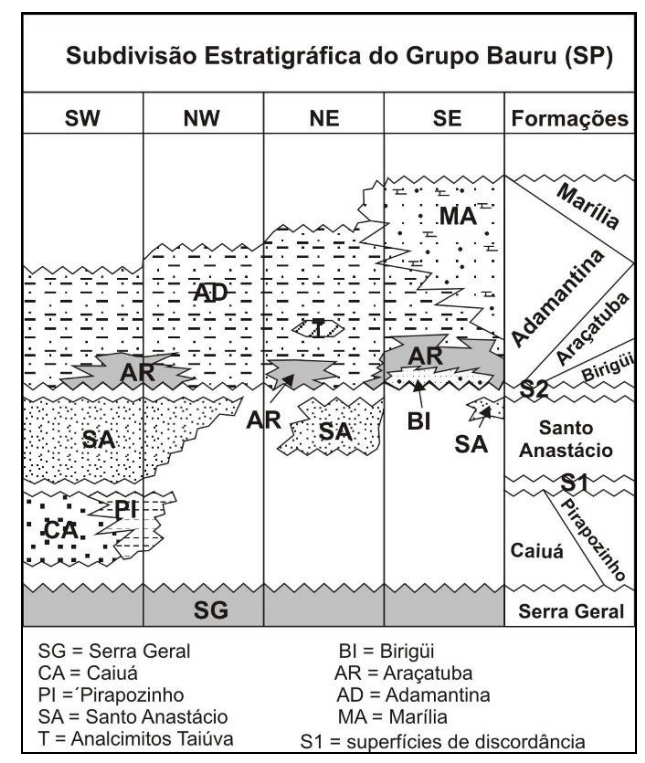

Figura 2. Subdivisão estratigráfica do Grupo Bauru (Paula e Silva, 2003).

Com base nessa litoestratigrafia, Paula e Silva et al. (2005) subdividiram o SAB nos aquíferos Marília, Adamantina, Birigui, Santo Anastácio e Caiuá, e aquitardos Araçatuba e Pirapozinho. Na área correspondente a esse estudo ocorrem somente os aquíferos Caiuá e Santo Anastácio.

O arcabouço sedimentar do Aquífero Caiuá, em subsuperfície, é descrito como um pacote predominantemente psamítico, constituído de arenitos avermelhados a marrom-acastanhados, de granulometria variando de muito fina a média com grãos de boa esfericidade, cobertos por película ferruginosa, subarredondados, em geral pouco argilosos e localmente com cimento calcífero. Por vezes ocorre, em sua porção basal, próximo ao contato com os basaltos da Formação Serra Geral, arenitos sílticos, marrom-avermelhados, médios, calcíferos (Paula e Silva, 2003).

O arcabouço sedimentar do Aquífero Santo Anastácio em subsuperfície caracteriza-se pelo predomínio de termos arenosos em detrimento de constituintes pelíticos. Para Paula e Silva (2003) a 
unidade apresenta caráter predominantemente arenoso e a análise de perfis revela padrões granulométricos predominantes do tipo cilíndrico, passando localmente para padrão de fining upward.

Os aquíferos Caiuá e Santo Anastácio são identificados como Bauru inferior/Caiuá no Mapa de Águas Subterrâneas do Estado de São Paulo (DAEE, 2005) tem caráter livre a localmente semiconfinado, granular, contínuo e uniforme, e permeabilidades variando de $1 \mathrm{~m} / \mathrm{dia}$ a $3 \mathrm{~m} / \mathrm{dia}$ (DAEE, 2005). Para esse conjunto, na região do Pontal do Paranapanema, o DAEE (2005) estima valores de transmissividade superiores a $100 \mathrm{~m}^{2} / \mathrm{dia}$, espessura saturada variando entre $150 \mathrm{~m}$ e 230 $\mathrm{m}$, capacidade específica média de $0,57 \mathrm{~m}^{3} / \mathrm{h} / \mathrm{m}$ a $1,6 \mathrm{~m}^{3} / \mathrm{h} / \mathrm{m}$, condutividade hidráulica entre 0,002 $\mathrm{m} /$ dia e 3,66 m/dia, porosidade efetiva entre $10 \%$ a $15 \%$, coeficiente de armazenamento específico da ordem de $10^{-1}$ e vazões de $40 \mathrm{~m}^{3} / \mathrm{h}$ a $80 \mathrm{~m}^{3} / \mathrm{h}$.

Segundo Campos (1987), as águas subterrâneas do SAB no Estado de São Paulo podem ser agrupadas em dois tipos dominantes: águas bicarbonatadas cálcicas e cálcio-magnesianas. Essas águas são de baixa salinidade e os íons $\mathrm{HCO}^{3-}, \mathrm{Ca}^{+2}$ e $\mathrm{Mg}^{+2}$ são os principais responsáveis pelo processo de enriquecimento salino das águas subterrâneas deste aquífero.

Para Barison (2003) as águas do aquífero Santo Anastácio são bicarbonatadas-cálcicas e cálcio-magnesianas, e as do Aquífero Caiuá são cálcio-magnesianas e sódicas. DAEE (2005) descreve as águas do SAB em geral como sendo de baixa salinidade, com concentrações salinas menores nos vales e à jusante dos rios interiores, enquanto as maiores concentrações são encontradas ao longo dos espigões de Pompéia-Adamantina e Valparaíso-Mirandópolis, no sudoeste paulista. Stradioto (2007), em pesquisa na região sudoeste de São Paulo, apontou predomínio de águas bicarbonatadas cálcicas e sódicas, secundariamente clorossulfatadas cálcicas e cloretadas sódicas, revelando a grande variação química que, segundo a autora, está relacionada à composição litológica do aquífero.

\section{MÉTODOLOGIA}

A caracterização hidrogeológica do assentamento baseou-se em dados obtidos com a perfuração de cinco poços tubulares para captação de água potável. A Figura 3 mostra a planta do assentamento com a localização dos poços instalados.

Nos poços 1 e 2 foi realizada a perfilagem de raios gama API, enquanto que nos demais foram “corridos" também os perfis de potencial espontâneo, resistividade normal, resistividade induzida e sônico compensado, calibrados conforme padrão API (American Petroleum Institute). 
A análise qualitativa de perfis permitiu identificar os melhores intervalos portadores de água, e auxiliou na inferência do ambiente deposicional. A análise quantitativa determinou a proporção de argila dos reservatórios arenosos e a porosidade total.

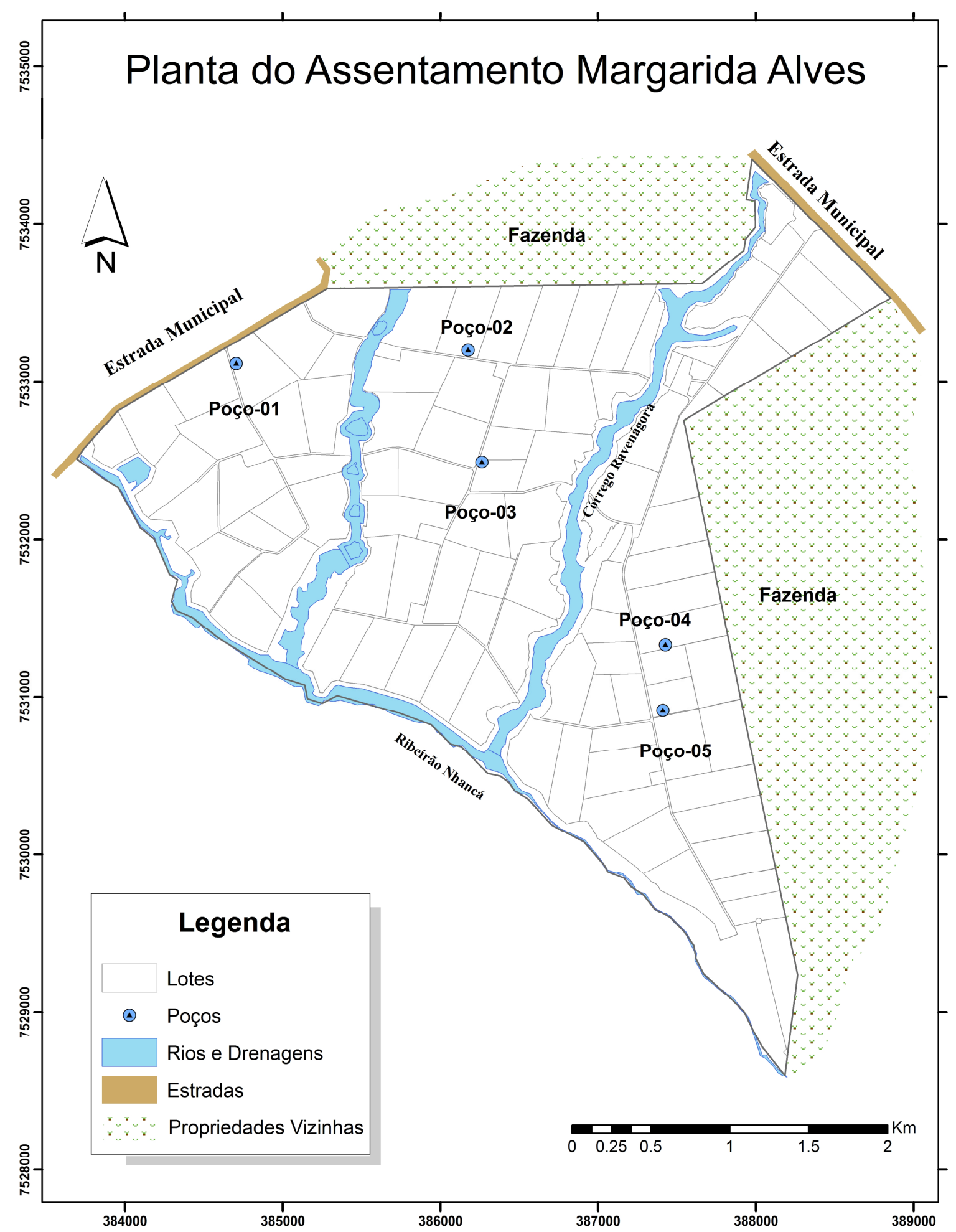

Figura 3. Planta do Assentamento Margarida Alves e localização dos poços de abastecimento. 
Os testes de produção foram realizados nos poços 2 e 5 , medindo-se o rebaixamento do nível de água durante o bombeamento por um período de 24 horas em vazão constante. Os dados obtidos foram interpretados pelos métodos de Theis e Cooper-Jacob, utilizando-se o programa AquiferTest Pro 3.5, da Waterloo Hidrogeologic Inc.

Os parâmetros $\mathrm{pH}$, condutividade elétrica e temperatura foram medidos em campo. Os cátions $\mathrm{Na}$ e $\mathrm{K}$ e os ânions $\mathrm{Cl}, \mathrm{NO}_{3}, \mathrm{SO}_{4}, \mathrm{CH}_{3} \mathrm{COO}$ foram analisados pelo método de cromatografia de íons. Os cátions $\mathrm{Ca}, \mathrm{Mg}, \mathrm{Zn}, \mathrm{Si}, \mathrm{Al}$ foram analisados pelo método de espectrometria de emissão atômica com fonte de plasma de argônio induzido, ICP-AES.

\section{RESULTADOS OBTIDOS}

A caracterização litológica dos sedimentos atravessados pelos poços foi baseada, principalmente, na interpretação de perfis geofísicos, auxiliada pela descrição de amostras de calha. A Tabela 1 resume as principais características dos poços instalados no assentamento.

\begin{tabular}{|l|c|c|c|c|c|l|l|}
\hline \multicolumn{2}{|l|}{ Tabela 1. Características dos poços instalados } \\
\hline Poço & $\begin{array}{c}\text { Coord. E } \\
(\mathrm{UTM})\end{array}$ & $\begin{array}{c}\text { Coord. N } \\
(\mathrm{UTM})\end{array}$ & $\begin{array}{c}\text { Cota } \\
(\mathrm{m})\end{array}$ & $\begin{array}{c}\text { Prof. } \\
\text { Total }(\mathrm{m})\end{array}$ & $\begin{array}{c}\text { N.E. } \\
(\mathrm{m})\end{array}$ & $\begin{array}{c}\text { Aquífero } \\
\text { Captado }\end{array}$ & $\begin{array}{c}\text { Intervalo de Filtros } \\
(\mathrm{m})\end{array}$ \\
\hline 01 & 384643,93 & 7533051,01 & 334,80 & 100 & 39,42 & S.A. & $55-95$ \\
\hline 02 & 386268,44 & 7533100,18 & 343,71 & 120 & 30,20 & S.A. & $50-60$ e $80-115$ \\
\hline 03 & 386196,32 & 7532425,12 & 327,03 & 170 & 39,20 & S.A./C & $70-110$ e $120-166$ \\
\hline 04 & 387364,61 & 7531266,04 & 323,08 & 150 & 29,30 & S.A./C & $70-138$ \\
\hline 05 & 387349,47 & 7530851,23 & 319,83 & 130 & 22,65 & S.A./C & $72-126$ \\
\hline
\end{tabular}

\section{S.A. - Santo Anastácio; C. - Caiuá}

Os poços 1 e 2 captam somente água do Aquífero Santo Anastácio (penetração parcial), enquanto que os demais (poços 3, 4 e 5) captam uma mistura de águas provenientes dos aquíferos Santo Anastácio e Caiuá, atravessando toda espessura do Grupo Bauru.

As espessuras da Formação Santo Anastácio variam de 90 metros, nos poços 4 e 5, a 120 metros, nos poços 2 e 3. As espessuras constatadas da Formação Caiuá nos poços 3, 4 e 5 são 50,60 e 40 metros respectivamente.

Os perfis da Figura 4 revelam desníveis decorrentes da conformação da superfície topográfica atual e do substrato deposicional basáltico, estes últimos responsáveis pelas variações de espessura da Formação Caiuá. A superfície de discordância S1 de Paula e Silva (2003) delimita o contato entre as formações Caiuá e Santo Anastácio. É possível observar distintos padrões de 
comportamento das curvas de resistividade e de raios gama, que permitem o reconhecimento destas duas unidades hidroestratigráficas em subsuperfície.

A porção central do assentamento, representada pelo perfil do poço 3, mostra maior espessura de sedimentos e representa o registro mais completo do Grupo Bauru na área. No poço 3 constatouse espessura de 125 metros de Formação Santo Anastácio, com alguns níveis de arenito com argilosidade muito baixa, comparativamente com o restante do perfil. Esses pacotes com baixos valores de raios gama são interpretados como reservatórios de melhor potencial hídrico. O poço 4 chega a apresentar 16 metros de arenitos com essa característica, o que sugere que a porção oriental da área seja potencialmente melhor produtora de água.

A Formação Caiuá é distinta por apresentar, comparativamente, padrão de raios gama mais homogêneo e seu topo posiciona-se abaixo da brusca mudança litológica, que marca o contato com a Formação Santo Anastácio. (Figura 4).

A Figura 5 apresenta as seções geoelétricas A-B, de direção geral NW-SE, e C-D, de direção $\mathrm{N}-\mathrm{S}$, com o intuito de estabelecer as correlações entre perfis. Nas duas seções é possível identificar a superfície S1, que separa as formações Caiuá e Santo Anastácio. Todavia, não é possível estabelecer uma correlação litofaciológica devido à baixa continuidade lateral de fácies, característica de depósitos fluviais.

O mapa potenciométrico elaborado com os dados de nível de água observados nos poços mostra que o sentido de fluxo regional de água subterrânea se dá em direção ao ribeirão Nhancá, que se configura como ponto de descarga local do SAB (Figura 6). A conformação da superfície potenciométrica exibida nesse mapa mostra que o SAB pode ser classificado, localmente, como de natureza livre, sugerindo interconexão entre os aquíferos presentes. 


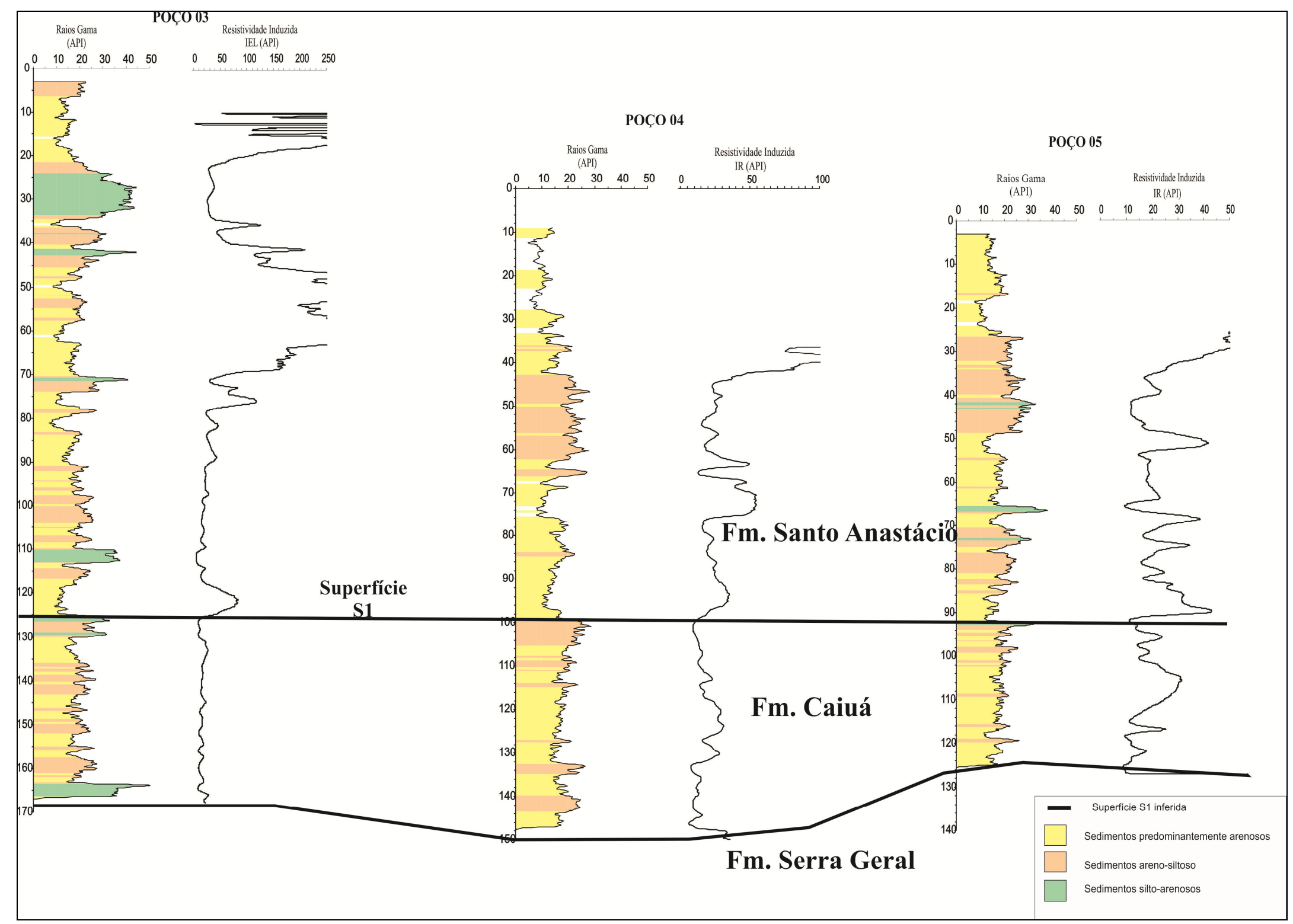

Figura 4. Interpretação litológica dos perfis geofísicos de raios gama 


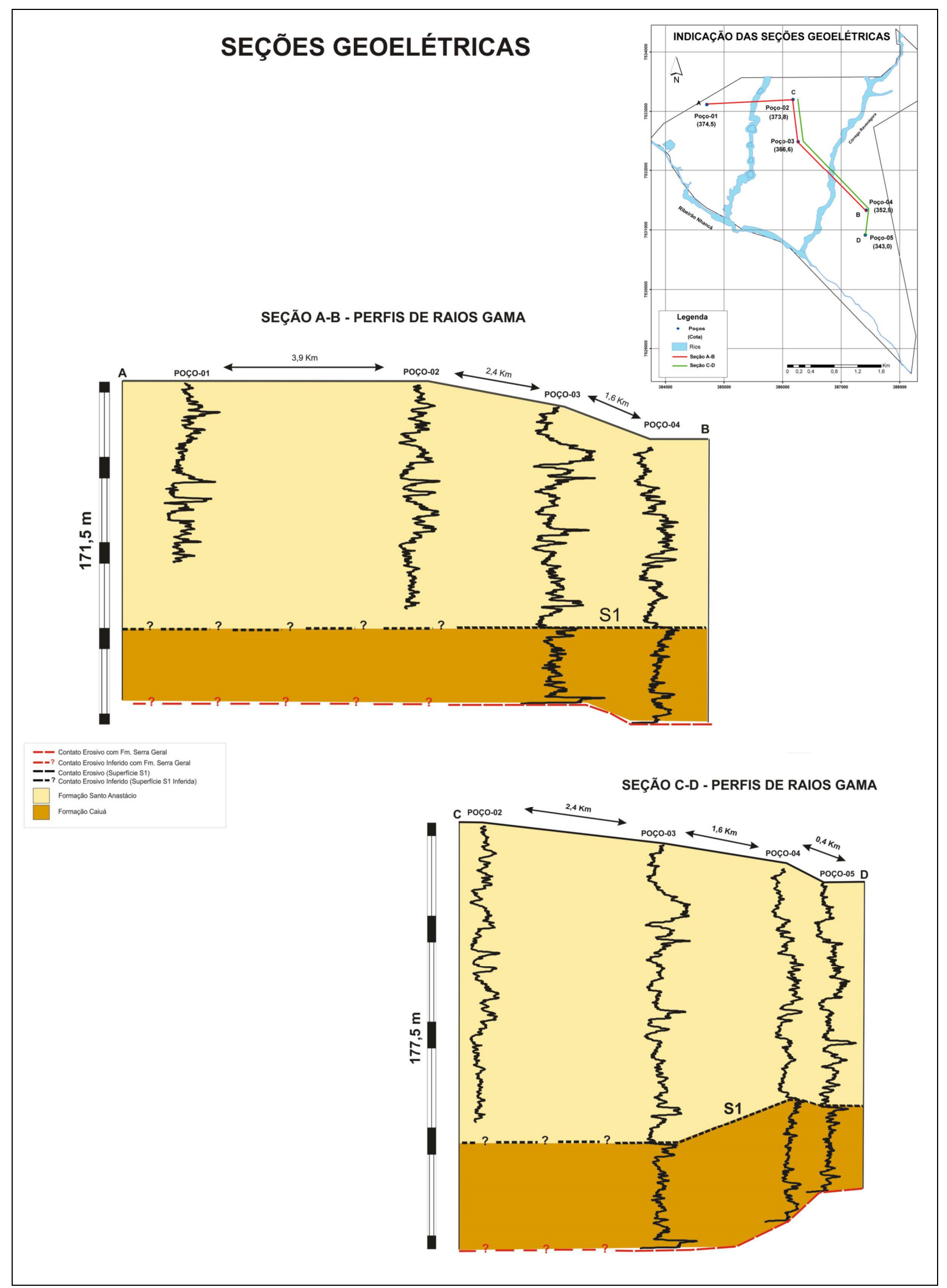

Figura 5. Seções geoelétricas 


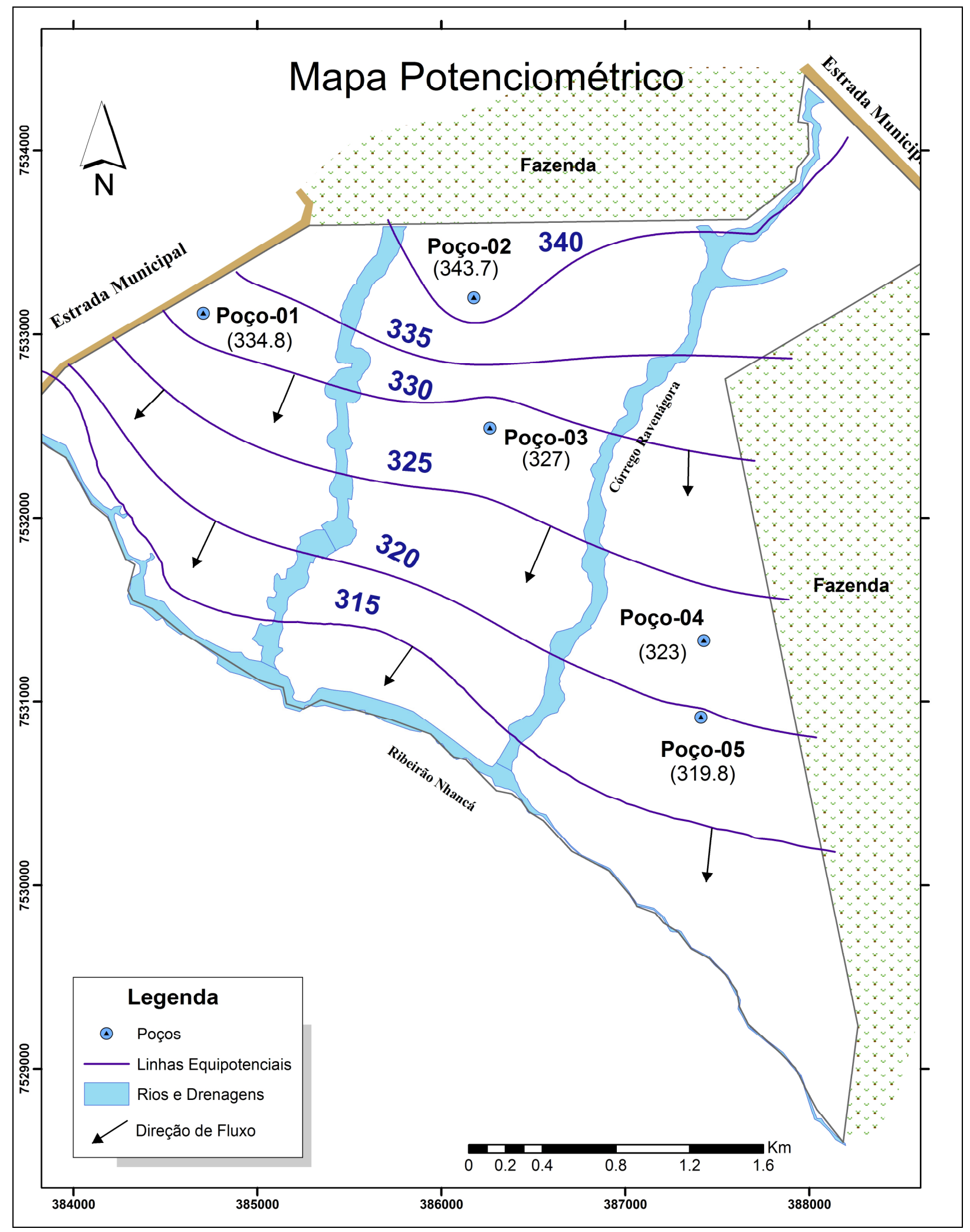

Figura 6. Mapa potenciométrico.

Valores de capacidade específica, transmissividade e condutividade hidráulica obtidos dos testes de produção realizados nos poços 2 (Aquífero Santo Anastácio) e 3 (Sistema Aquífero Caiuá/Santo Anastácio) são apresentados na Tabela 2. Os valores de condutividade hidráulica 
obtidos são pouco inferiores aos apresentados pelo DAEE (2005) e indicam que neste local as duas unidades hidroestratigráficas explotadas possuem características hidrodinâmicas similares.

\begin{tabular}{|c|c|c|c|c|l|c|c|}
\hline \multicolumn{7}{|c|}{ Tabela 2. Parâmetros obtidos nos testes de bombeamento } \\
\hline Poço & $\begin{array}{c}\text { N.E. } \\
(\mathrm{m})\end{array}$ & $\begin{array}{c}\text { N.D. } \\
(\mathrm{m})\end{array}$ & $\begin{array}{c}\text { Vazão } \\
\left(\mathrm{m}^{3} / \mathrm{h}\right)\end{array}$ & $\begin{array}{c}\text { Capacidade } \\
\text { Específica }\end{array}$ & $\begin{array}{c}\text { Método } \\
\text { Interpretação }\end{array}$ & $\begin{array}{c}\text { Transmissividade } \\
\left(\mathrm{m}^{2} / \mathrm{d}\right)\end{array}$ & $\begin{array}{c}\text { Condutividade } \\
\text { Hidráulica } \\
(\mathrm{m} / \mathrm{d})\end{array}$ \\
\hline 2 & 30,53 & 32,27 & 6,5 & 3,7 & Theis & 81,7 & 0,63 \\
\cline { 6 - 8 } & 23,30 & 28,01 & 12 & 2,5 & Cooper-Jacob & 154,0 & 1,18 \\
\cline { 5 - 8 } & & & & & Theis & 86,5 & 0,83 \\
\hline
\end{tabular}

O conteúdo de matriz pelítica das rochas, designado "argilosidade", influencia nas propriedades de permoporosidade e é responsável pela diminuição da resistividade e aumento dos valores de raios gama registrados nos perfis, característica esta que permite distinguir reservatórios mais, ou menos permeáveis. Desse modo, adotou-se uma linha de corte em 20 API para diferenciar reservatórios mais permeáveis (valores $\leq 20$ API) de reservatórios menos permeáveis e/ou impermeáveis (valores $\geq 20$ API). As espessuras individuais dos reservatórios mais permeáveis de cada poço foram somadas (Tabela 3) e os dados resultantes foram interpolados no programa ARCGIS v. 9.3 para gerar mapas de isólitas de areia (Figura 7).

Para a Formação Santo Anastácio o mapa de isólitas de areias indica haver maiores espessuras de areia na porção central da área, com 62 \%, e também na porção SE, com $63 \%$, indicando serem essas as melhores áreas produtoras de água no assentamento.

Tabela 3. Resumo das informações dos corpos de areia

\begin{tabular}{|c|c|c|c|c|c|c|c|c|c|}
\hline Poço & $\begin{array}{c}\text { Espes. } \\
\text { Total } \\
\text { S.A. (m) }\end{array}$ & $\begin{array}{c}\text { Espes. } \\
\text { Areia } \\
\text { S.A. (m) }\end{array}$ & $\begin{array}{c}\text { Percent. } \\
\text { Areia } \\
\text { S.A. (\%) }\end{array}$ & $\begin{array}{l}\text { Espes. } \\
\text { Total } \\
\text { C. (m) }\end{array}$ & $\begin{array}{l}\text { Espes. } \\
\text { Areia } \\
\text { C. (m) }\end{array}$ & $\begin{array}{c}\text { Percent. } \\
\text { Areia } \\
\text { C. }(\%)\end{array}$ & $\begin{array}{l}\text { Profund. } \\
\text { Avaliada } \\
\text { Perfil } \\
\text { Geofísico } \\
\text { (m) }\end{array}$ & $\begin{array}{c}\text { Espes. } \\
\text { Total de } \\
\text { Areia } \\
\text { (m) }\end{array}$ & $\begin{array}{c}\text { Total } \\
\text { Areia } \\
(\%)\end{array}$ \\
\hline 1 & 99 & 39 & $39 \%$ & - & - & - & 99 & 39 & $39 \%$ \\
\hline 2 & 118 & 53 & $45 \%$ & - & - & - & 118 & 53 & $45 \%$ \\
\hline 3 & 125 & 78 & $62 \%$ & 41 & 21 & $51 \%$ & 166 & 99 & $60 \%$ \\
\hline 4 & 100 & 37 & $37 \%$ & 37 & 35.5 & $96 \%$ & 137 & 72.5 & $53 \%$ \\
\hline 5 & 92 & 58 & $63 \%$ & 33 & 27.5 & $83 \%$ & 125 & 85.5 & $68 \%$ \\
\hline
\end{tabular}

- Não atingiu a formação

S.A. - Formação Santo Anastácio; C. - Formação Caiuá. 
O mapa de isólitas de areias para a Formação Caiuá indica um aumento do teor de areia nessa unidade em relação à Formação Santo Anastácio, sendo composta, em média, por 77\% de areia, e chegando a atingir 96\% (Poço 4).

No mapa de isólitas totais verifica-se que a metade oriental da área tem constituição predominantemente arenosa, ocorrendo um incremento na direção SE.

A porosidade total foi calculada por meio da equação de Raymer-Hunt (RAYMER et al., 1980), utilizada para rochas pouco consolidadas ou com porosidade total inferior a $30 \%$.

$$
\phi t=0,625 \times\left(\frac{\Delta t-\Delta t m}{\Delta t}\right)
$$

Onde,

$\Delta t m$ é o tempo de trânsito da onda sonora na matriz

$\Delta t$ é o tempo de trânsito da onda sonora lido no perfil

O perfil sônico fornece uma medida a cada $10 \mathrm{~cm}$, sendo calculada a porosidade total para cada leitura e a média a cada metro, apenas para os corpos arenosos com baixo conteúdo de argila dos poços 3, 4 e 5. A porosidade média resultante foi de $32 \%$ para a Formação Santo Anastácio e $28 \%$ para a Formação Caiuá. 


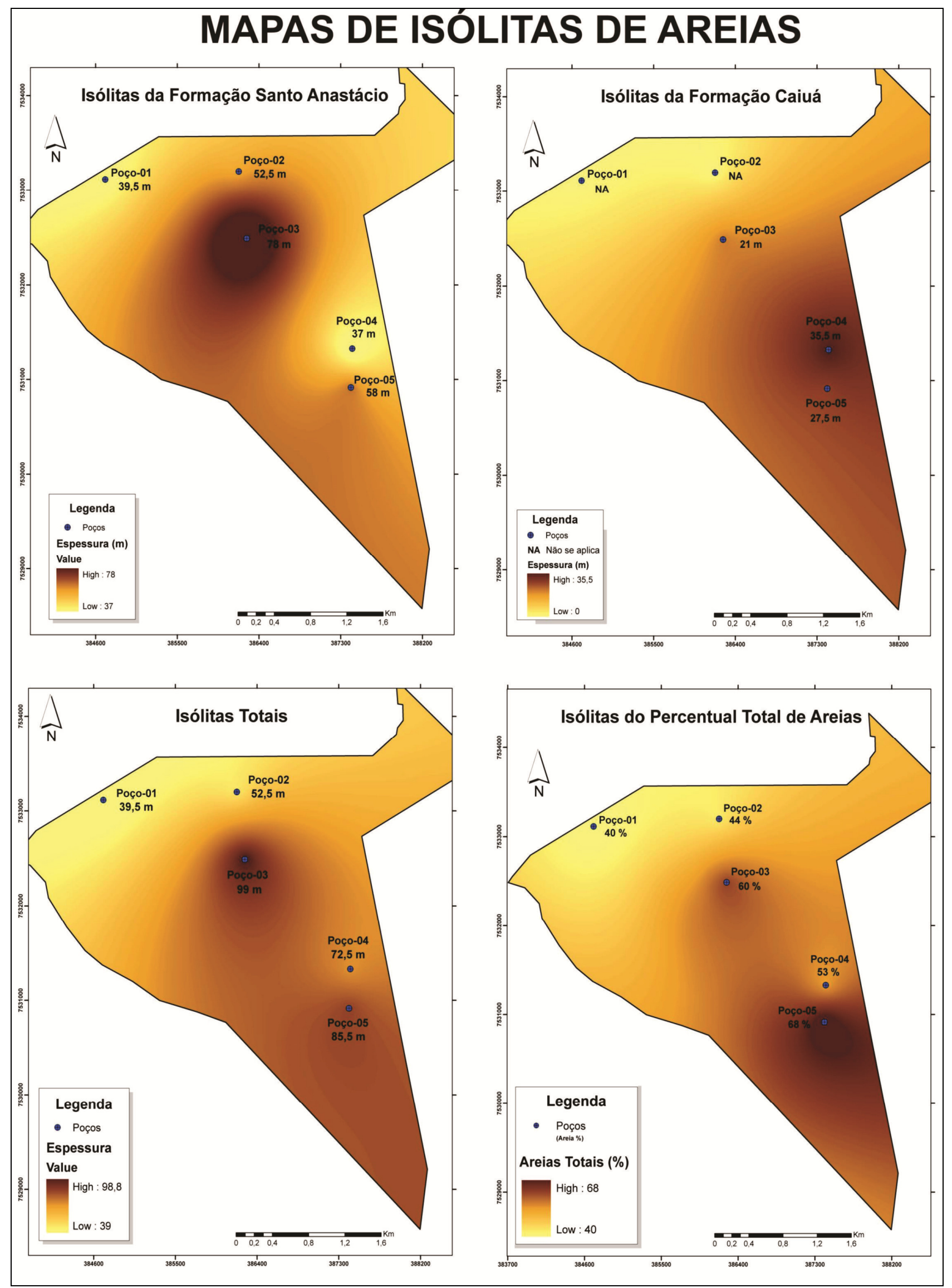

Figura 7. Mapas de isólitas de areia do SAB na área do assentamento Margarida Alves. 
Foram analisadas amostras de água subterrânea dos poços 1, 2, 3 e 5, cujos resultados encontram-se na Tabela 4. A condutividade elétrica média foi de 43,88 $\mu \mathrm{S} / \mathrm{cm}$ e o $\mathrm{pH}$ de 6,58.

\begin{tabular}{|c|c|c|c|c|c|c|c|c|c|c|c|c|}
\hline \multicolumn{1}{|l|}{ Tabela 4. Principais parâmetros analisados nas águas subterrâneas (meq/L) } \\
\hline Amostra & $\mathrm{Na}$ & $\mathrm{K}$ & $\mathrm{Ca}$ & $\mathrm{Mg}$ & $\mathrm{Cl}$ & $\mathrm{HCO}_{3}$ & $\mathrm{SO}_{4}$ & $\mathrm{Al}$ & $\mathrm{SiO}_{2}$ & $\mathrm{NO}_{3}$ & $\begin{array}{c}\text { S.T.D. } \\
(\mathrm{mg} / \mathrm{L})\end{array}$ & $\begin{array}{c}\text { Balanço } \\
\text { Iônico } \\
(\%)\end{array}$ \\
\hline Poço-01 & 0,059 & 0,088 & 0,056 & 0,064 & 0,039 & 0,154 & - & - & 0,37 & 0,046 & 43,89 & 5,60 \\
\hline Poço-02 & 0,102 & 0,091 & 0,178 & 0,102 & 0,043 & 0,329 & - & 0,001 & 0,41 & 0,051 & 61,84 & 5,44 \\
\hline Poço-03 & 0,108 & 0,082 & 0,369 & 0,147 & 0,036 & 0,505 & - & - & 0,40 & 0,123 & 80,24 & 3,16 \\
\hline Poço-05 & 0,128 & 0,071 & 0,447 & 0,141 & 0,018 & 0,710 & 0,004 & - & 0,57 & 0,017 & 98,46 & 2,48 \\
\hline
\end{tabular}

A distribuição dos diagramas Stiff (Figura 8) ressalta a diferença química entre as águas dos aquíferos Santo Anastácio e Caiuá, sendo que esse último apresenta maiores concentrações de cálcio e bicarbonato comparativamente às amostras do Aquífero Santo Anastácio (poços 1 e 2).

A amostra de água subterrânea do poço 1, que se localiza na cota mais alta da área e capta água a 50 metros de profundidade, apresenta menor mineralização. No geral, as águas amostradas são fracamente mineralizadas, apresentam baixos teores de $\mathrm{Mg}, \mathrm{Ca}$ e $\mathrm{Na}+\mathrm{K}$, e podem ser classificadas como bicarbonatadas magnesianas a bicarbonatadas cálcicas. 


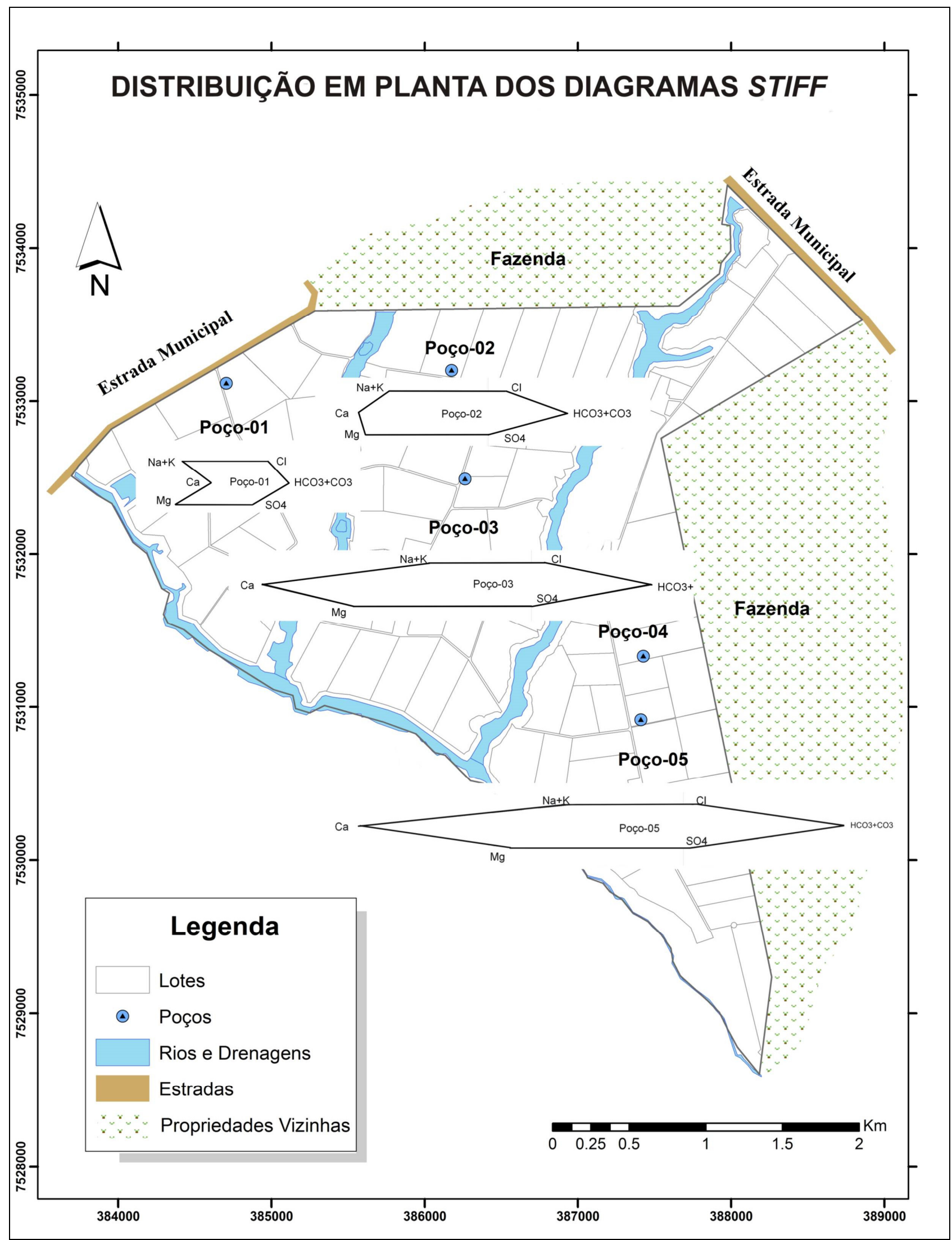

Figura 8. Distribuição em planta dos diagramas Stiff. 


\section{CONSIDERAÇÕES FINAIS}

A interpretação de perfis geofísicos integrada aos dados hidrodinâmicos e hidroquímicos de poços tubulares compõem importante instrumento para o entendimento de arcabouços hidrogeológicos.

Os perfis permitiram distinguir as formações Santo Anastácio e Caiuá, em subsuperfície, mostrando os ciclos de fining upward, a interdigitação de camadas arenosas e areno-siltosas e a variação faciológica entre os poços estudados, feições estas características de depósitos sedimentares originados em ambiente fluvial.

As unidades hidroestratigráficas do Sistema Aquífero Bauru têm caráter livre e apresentam águas com composições químicas distintas. O Aquífero Santo Anastácio apresenta-se menos mineralizado que o Aquífero Caiuá que contém concentrações maiores de cálcio e bicarbonatos. Para o Aquífero Santo Anastácio, isoladamente, as águas foram classificadas como bicarbonatadas magnesianas, enquanto as do $\mathrm{SAB}$ foram classificadas como bicarbonatadas cálcicas.

\section{REFERÊNCIAS BIBLIOGRÁFICAS}

BARISON, M.R. 2003. Estudo hidrogeoquímico da porção meridional do sistema aquífero Bauru no Estado de São Paulo. Tese de Doutorado. 158 p. Instituto de Geociências e Ciências Exatas. Universidade Estadual Paulista - UNESP. http://repositorio.unesp.br/.

CAMPOS, H.C.N.S. 1987. Contribuição ao estudo hidrogeoquímico do Grupo Bauru no Estado de São Paulo. São Paulo. SP. 157p. Instituto de Geociências, Universidade de São Paulo. http://www.teses.usp.br/.

COMPANHIA DE PESQUISAS DE RECURSOS MINERIAIS - CPRM. 2003. Mapa Geológico do Estado de São Paulo. Escala 1:750 000. CD-ROM. www.cprm.gov.br.

DEPARTAMENTO DE ÁGUAS E ENERGIA ELÉTRICA - DAEE. 1990. Plano estadual de recursos hídricos: Primeiro plano do Estado. Síntese. 97 p. http://www.sigrh.sp.gov.br/planoestadualderecursoshidricos.

DEPARTAMENTO DE ÁGUAS E ENERGIA ELÉTRICA - DAEE (org.). 2005. Mapa hidrogeológico do Estado de São Paulo. Escala 1:500.000. CD-ROM. http://www.daee.sp.gov.br/acervoepesquisa/mapasub/MAPA_AS.pdf.

PAULA E SILVA F. 2003. Geologia de subsuperfície e hidroestratigrafia do Grupo Bauru no Estado de São Paulo. Tese de Doutorado. 166 p. Instituto de Geociências e Ciências Exatas, Universidade Estadual Paulista - UNESP. http://repositorio.unesp.br/. 
PAUlA E Silva F., CHANG H. K. \& CAETANO-CHANG M. R. 2005. Perfis de referência do Grupo Bauru (K) no Estado de São Paulo. p.21-32. Revista Geociências - V22. http://www.revistageociencias.com.br/.

PAULA E SILVA F., CHANG H.K. , CAETANO-CHANG M. R \& STRADIOTO M.R. 2006. Sucessão Sedimentar do Grupo Bauru na Região de Pirapozinho (SP). p.17-26. Revista Geociências - V25. http://www.revistageociencias.com.br/.

RAYMER, L. L.; HUNT, E. R. \& GARDNER, J. S. 1980. An improved sonic transit time-toporosity transform. Trans. SPWLA 21st Annu. Log. Symp., Paper P.

STRADIOTTO M.R. 2007. Hidroquímica e aspectos diagenéticos do sistema aquífero Bauru na região sudoeste do Estado de São Paulo. Tese de Mestrado. 161p. Instituto de Geociências e Ciências Exatas. Universidade Estadual Paulista - UNESP. http://repositorio.unesp.br/. 